\title{
Assessment of Malaria Risk Using GIS and Multi Criteria: The Case Study of East Gojjam Zone, Ethiopia
}

\author{
Abinet Addis \\ Department of Civil Engineering, Debre Markos University, Debre Markos, Ethiopia
}

\begin{abstract}
Malaria is one of the most severe public health problems worldwide with 300 to 500 million cases and about one million deaths reported to date, $90 \%$ of which were reported from Sub Saharan African countries like Ethiopia. The main objective of the study was Assessment of malaria risk areas by using the GIS-based MCA approaches in East Gojjam zone. Weighted overlay technique of multi-criteria analysis was used to develop the malaria risk map. The malaria risk map was produced depending upon the overlay analysis of the malaria hazard map and some factors like land use land cover, population density, health stations. The malaria risk map was classified into four suitability index such as very highly suitable, high suitable, moderately suitable, and low suitable. The result shows that around $21.02 \%$ areas is very highly suitable for malaria risk, $24.49 \%$ is high suitable, $24.66 \%$ is moderately suitable and $29.83 \%$ is low suitable for malaria risk areas.
\end{abstract}

Keywords: East Gojjam Zone, Arc GIS, Malaria risk.

DOI: $10.7176 / \mathrm{CER} / 12-12-03$

Publication date: December $31^{\text {st }} 2020$

\section{INTRODUCTION}

Malaria is a mosquito-borne life-threatening infectious disease of humans, caused by parasites that are transmitted to people through the bites of infected mosquitoes (Chakarova et al., 2015; Addisu, 2015). Malaria is pervasive to Ethiopia; $75 \%$ of the landscape areas below $2000 \mathrm{~m}$ above sea level is malarias which is fertile low land areas and suitable for agriculture. More than 54 million populations live in these areas and are at risk of malaria (Ayalew, 2016; Mulugojjam, 2015). The distribution and transmission of malaria in Ethiopia varies from place to place. For example, the distribution of malaria in Ethiopia is largely determined by altitude. Altitude affects the pattern of malaria distribution in Ethiopia through its effect on temperature (Betemariam et al., 2002).

Malaria as a vector borne disease whose transmission and risk levels depend on environmental and anthropogenic factors, any changes in temperature, rainfall, relative humidity, vegetation cover types amongst others factors results in major impact on malaria transmission (Obsomer, 2007). Temperature for instance affects mosquito development rate and final survival of the adult mosquitoes. Vegetation types, population density, poverty levels together with other development and social economic factors also greatly influence malaria risk levels in a given locality (Onyango, 2016; Sujoy et al., 2016).

Geographic Information Systems are a useful tool to generate interactive malaria risk maps allowing the management and analysis of multiple databases taking into account the geographical component of the different risk factors (Ribo A. et al., 2016). Multiple criteria decision analysis approaches are used to deal with the difficulties that decision-makers encounter in handling large extents of complex information. The principle of the method is to divide the decision problems into smaller understandable parts, to analyze each part separately and then to integrate the parts in a logical manner (Malczewski, 1997). The purpose of this study is to use ArcGIS tools to assess the malaria risk areas in the study area integrated with multi-criteria method, which consists of weighted linear combination (WLC) methods.

\section{MATERIALS AND METHODS}

\subsection{Methods}

In this Research Methodology, the spatial analysis tools provided by the ArcGIS software integrated with the multi-criteria analysis procedure to identify malaria risk areas from the entire study area. The process of identifying malaria risk area was employed in this study is shown in (Fig. 2). In this study, nine factors were identified, such as land use land cover, surface water, soil types, and slope, altitude and population density, health stations, rainfall and temperature. All the above listed factors were classified into three categories of Hazard, Element at risk and Vulnerability map. Finally, produce malaria risk map by integrated weighted hazard map, element risk map and vulnerability map to identify malaria risk areas of the study area. 


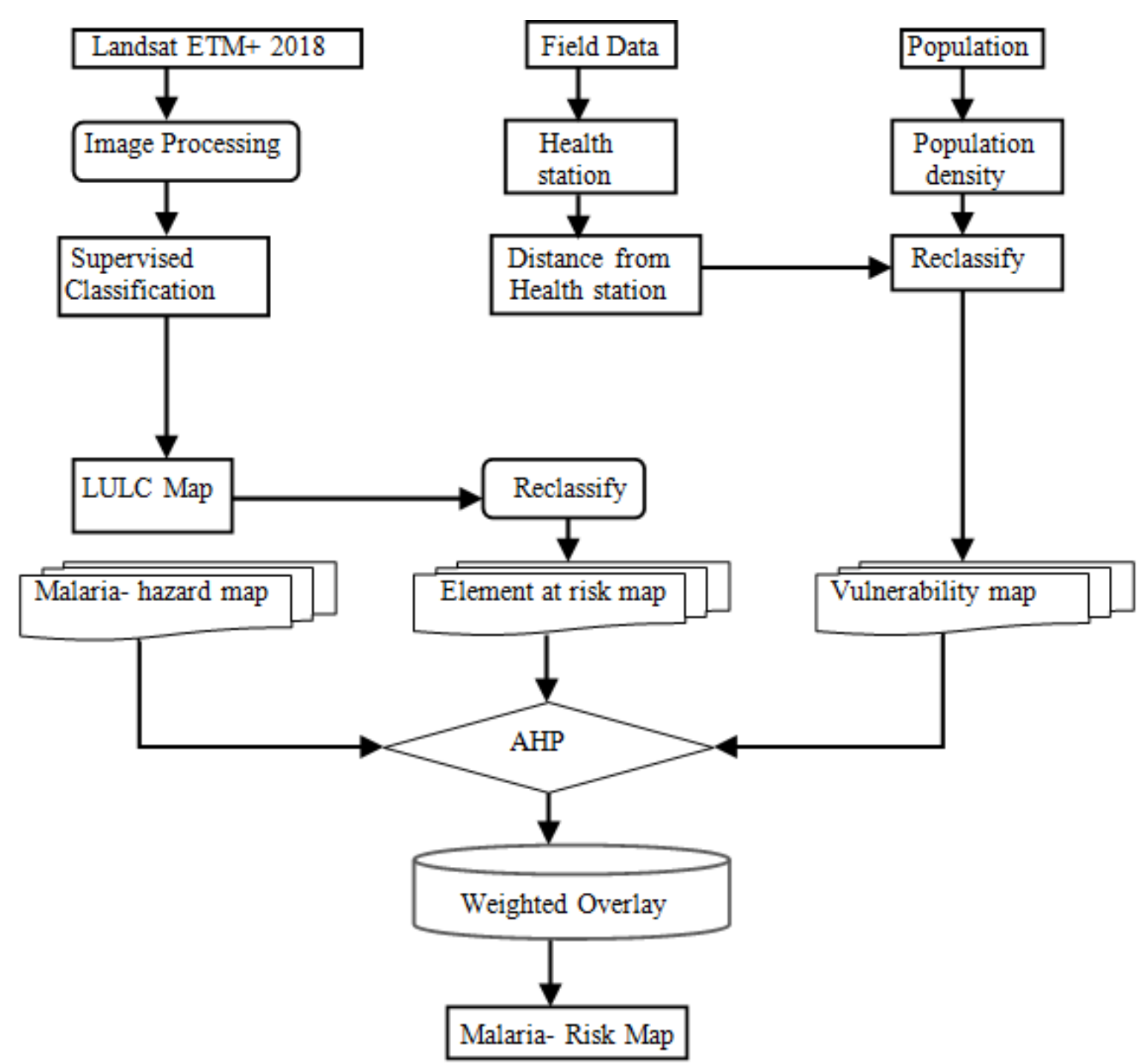

Fig. 2: Flow chart of methodology

\section{RESULTS AND DISCUSSION}

\subsection{Factors for Identify Malaria Risk Areas}

\subsubsection{Population Density}

The Population density was taken as vulnerability that affect by malaria incidence. The population density data were calculated from the national census population projections for 1999. Gross population density calculation method is to calculate the number of person per square kilometers. Then population shape file was converted to raster layer using conversion tools/feature to raster. Then further the data layer was reclassified into four sub factors which are classified using equal interval method. And new values re-assigned in order of increasing number of population that is more susceptible to malaria vulnerability. The population density was reclassified in the assumption that the denser the population, the more vulnerable it will be to malaria risk. 


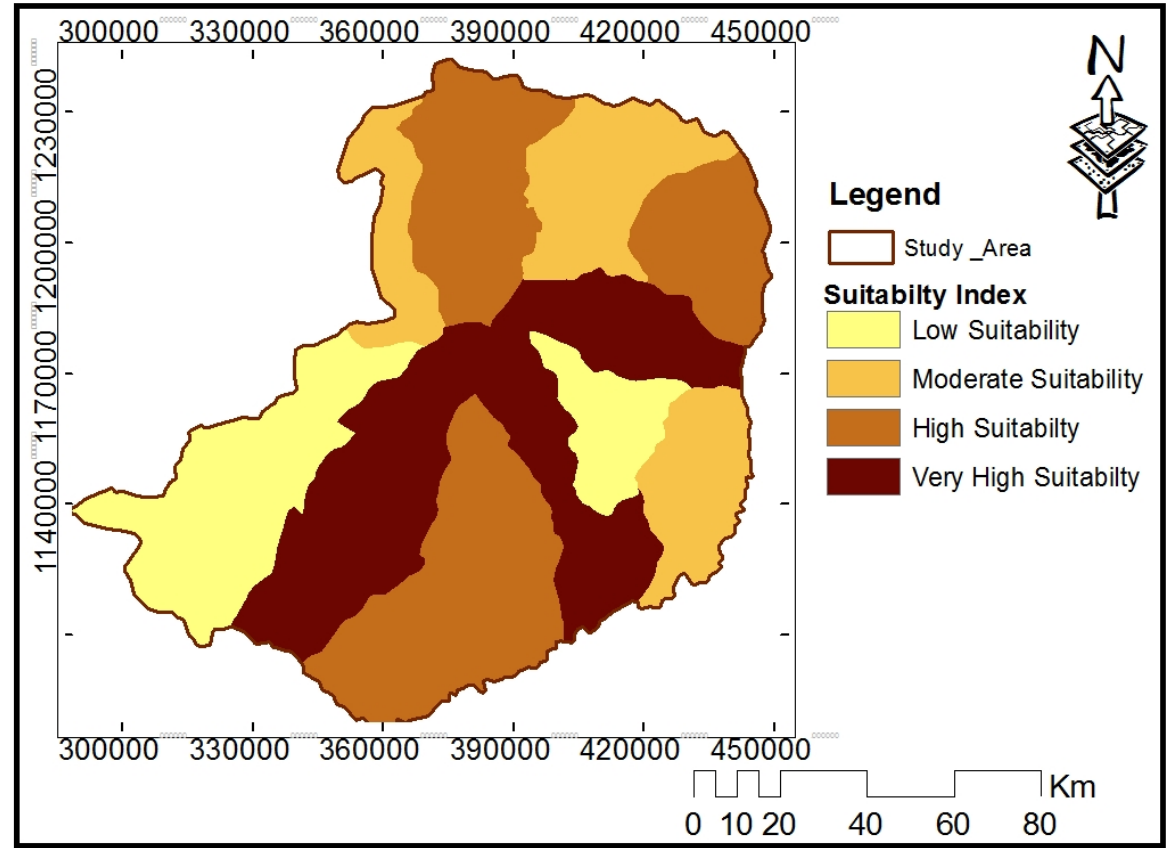

\subsubsection{Distance from Health stations}

Fig.3: population density map

Presence of health institutions in a particular area is very important for reduction of disease, awareness creation about different diseases and their means of prevention, easily accessibility and fair cost of treatment. These in turn influence the prevalence of a particular disease. Absence and distant health institutions result in difficulties in accessibility and high cost of treatment. Therefore, people who are near to health institutions are safer relative to those who are at farther places and takes lower risk level.

To identify health institutions accessibility and for their effect for those inaccessible areas, spatial location of health institutions within the study area were collected with GPS on field survey for accessible areas and from Woreda Health Office for those at remote and accessibility were limited. There are 13 health institutions were collected from the study area of east Gojjam zone weredas. According to WHO (2003), areas found within $3 \mathrm{Km}$ radius from a health facility is assumed to be less risky than areas found beyond this distance.

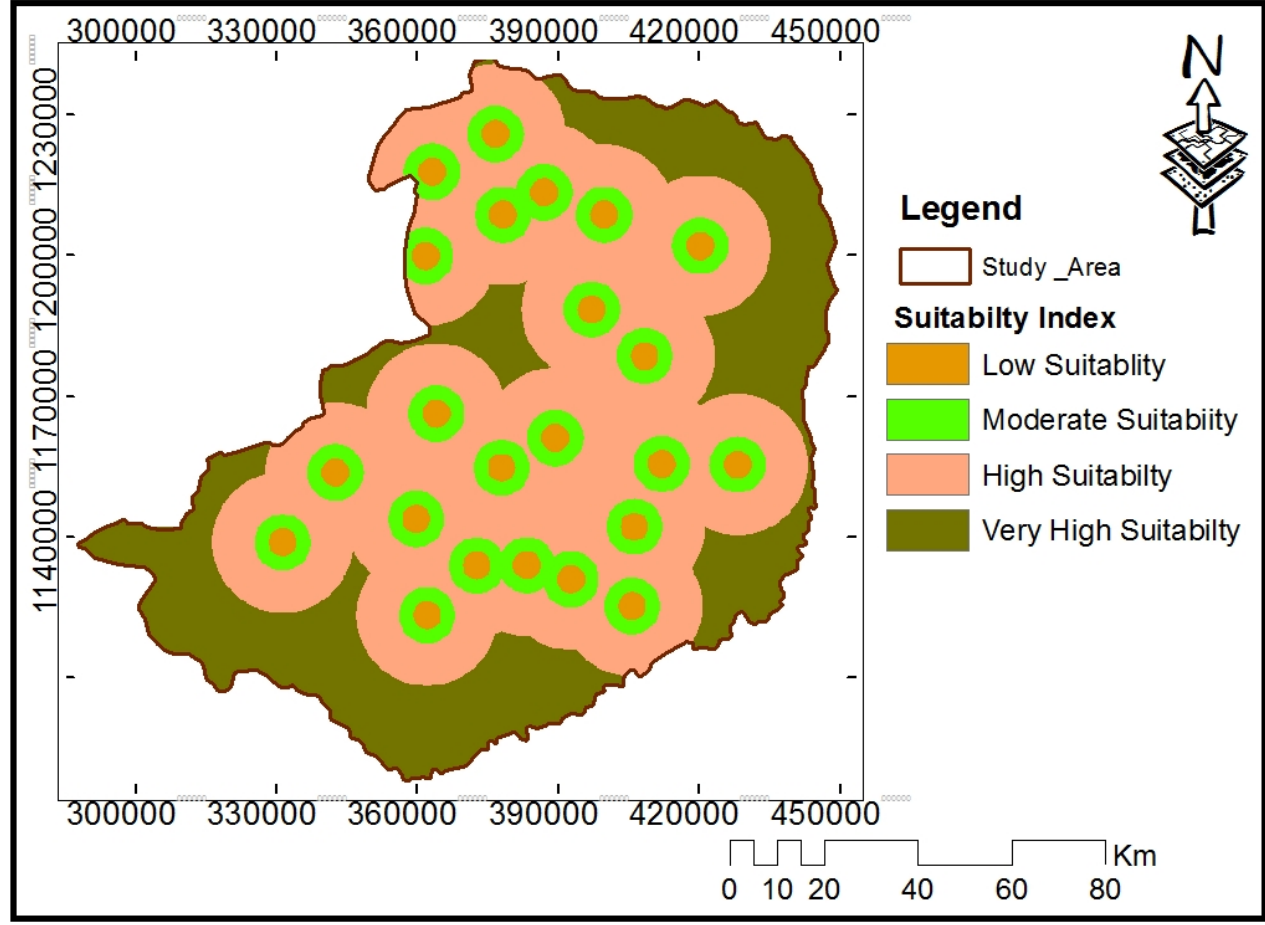

Fig.4: Health stations map 


\subsubsection{Land cover/ Land use (LCLU)}

Land cover and land use type of an area are important risk factors to malaria transmission. Marsh clearance, dam construction and crop cultivation also increase the risk of malaria at local scale (Bindu B., and Janak PJ., 2014). The land use land cover was taken as element at risk that affect by malaria occurrence (A. Ahmed, 2014; Tensaye W., 2016; Emebet D., et al., 2016; Dilip K. et al., 2016). Thus the whole idea behind this is to identify which particular land use type or land cover types are more prone to be affected by malaria incidence or which land use land cover can exacerbate the incidence of malaria. As for example, increasing of more settlements in urban areas can leads to increase of malaria incidence (Dilip K. et al., 2016). The LULC map was prepared with the help freely downloadable satellite images of Land sat 8 ETM +30 meter resolution. The image was reclassified into different LULC classes using the manual training sampling technique and maximum likelihood algorithm. This was classified into four classes such as bare land, farm land, built up area and water body.

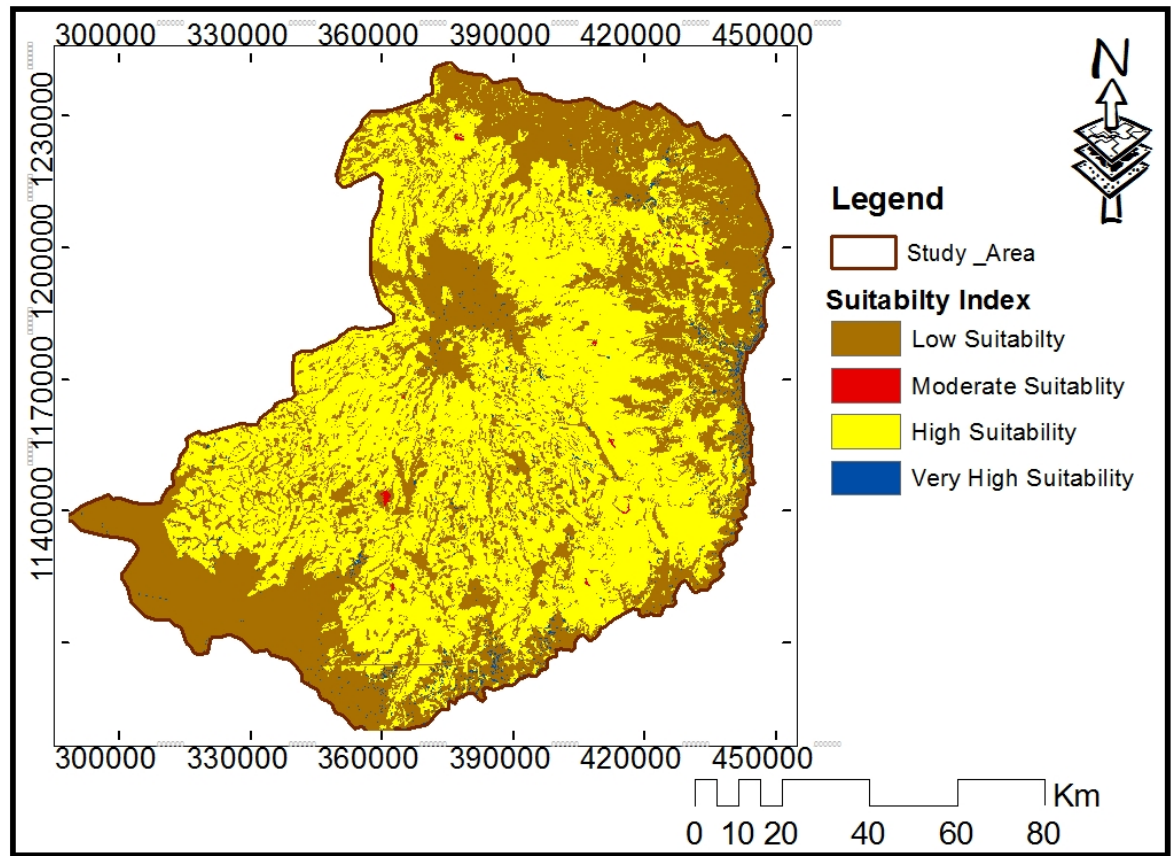

\subsubsection{Malaria Hazard Map}

Fig.5: Land use Land cover map

In this study, some of the factors are considered to identify malaria hazard areas. The factors are elevation, slope, and distance from rivers, rainfall, and temperature and soil types of malaria occurrence in the study area. It determines number of occurrence of mosquitoes in an area, thus these leads to overlaying of each factor to establish and identify malaria hazard in an area. The malaria hazard map that was prepared was derived from several factors. The factors were ranked, according to the degree of importance that have for the occurrence of malaria in an area. Due to different opinions and views in assigning rankings and weightings to each factor and their classes based on the previous studies and experts by using weighted linear combination method. In this study, the final output map of malaria hazard after overlaying six factors namely; Altitude, slope, distance from rivers, temperature, rainfall and soil types was weighted and ranked in ArcGIS 10.4 using weighted overlay analysis tool, shown the following (Figure 6). 


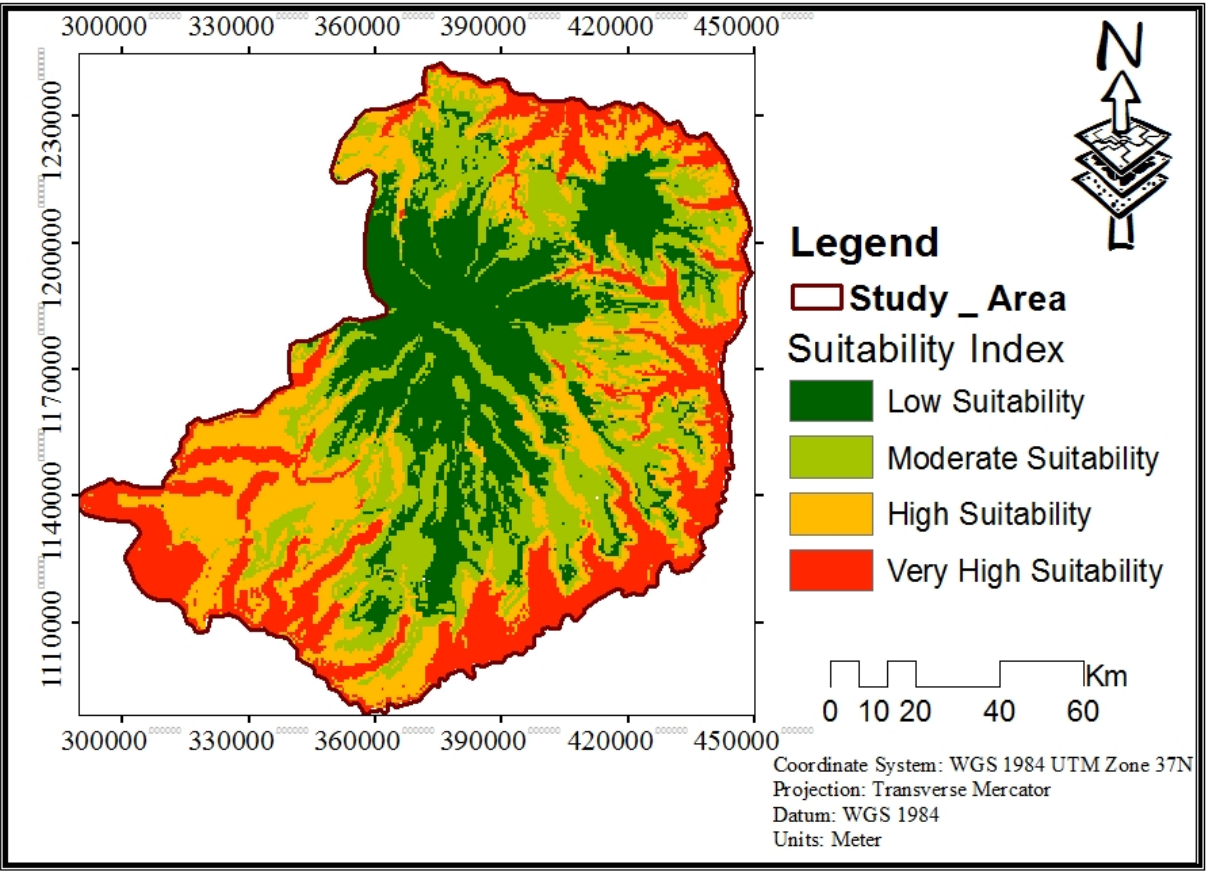

Fig.6: Malaria Hazard map

\subsection{Identified Malaria Risk Areas}

The malaria hazard mapping which is based only on natural conditions is not sufficient to locate the malaria risk area but need to include socio economic factors that have the profound effect for the survival of the vector Anopheles mosquitoes. These factors including population density, health stations and land use land cover as well as the hazard map of the study area. The basis for the calculation of the map was the risk computation model (Risk $=$ Hazard * Element at Risk * Vulnerability) developed by shook (1997).

Table 1: Summary of classification, ranking and weighting of malaria risk factors

\begin{tabular}{|c|c|c|c|c|}
\hline Factor & Weight & Class & Rank & Degree of risk \\
\hline \multirow{4}{*}{ Hazard } & \multirow{4}{*}{$60 \%$} & & 1 & Low Suitability \\
\hline & & & 2 & Moderate Suitability \\
\hline & & & 3 & High Suitability \\
\hline & & & 4 & Very High Suitability \\
\hline \multirow{4}{*}{ LULC } & \multirow{4}{*}{$20 \%$} & Bare land & 1 & Low Suitability \\
\hline & & Farm land & 2 & Moderate Suitability \\
\hline & & Built up areas & 3 & High Suitability \\
\hline & & Water body & 4 & Very High Suitability \\
\hline \multirow{4}{*}{$\begin{array}{l}\text { Distance from Health } \\
\text { stations (meter) }\end{array}$} & \multirow{4}{*}{$5 \%$} & $0-3000 \mathrm{~m}$ & 1 & Low Suitability \\
\hline & & $3000-6000 \mathrm{~m}$ & 2 & Moderate Suitability \\
\hline & & $6000-9000 \mathrm{~m}$ & 3 & High Suitability \\
\hline & & $>9000 \mathrm{~m}$ & 4 & Very High Suitability \\
\hline \multirow{4}{*}{$\begin{array}{l}\text { Population Density } \\
\quad\left(\text { pop } / \mathrm{km}^{2}\right)\end{array}$} & \multirow{4}{*}{$15 \%$} & $122-166$ & 1 & Low Suitability \\
\hline & & $166-209$ & 2 & Moderate Suitability \\
\hline & & $209-253$ & 3 & High Suitability \\
\hline & & $253-296$ & 4 & Very High Suitability \\
\hline
\end{tabular}

A malaria risk map was produced in an overlay weighted process in ArcGIS environment indicating the potential risk of malaria at any point within the study area in relation to land use land cover (Element at risk layer ), population density and Health stations (Vulnerability layer) and malaria hazard. To create the malaria risk map of the study area, each variable were reclassified as shown in table 1. 


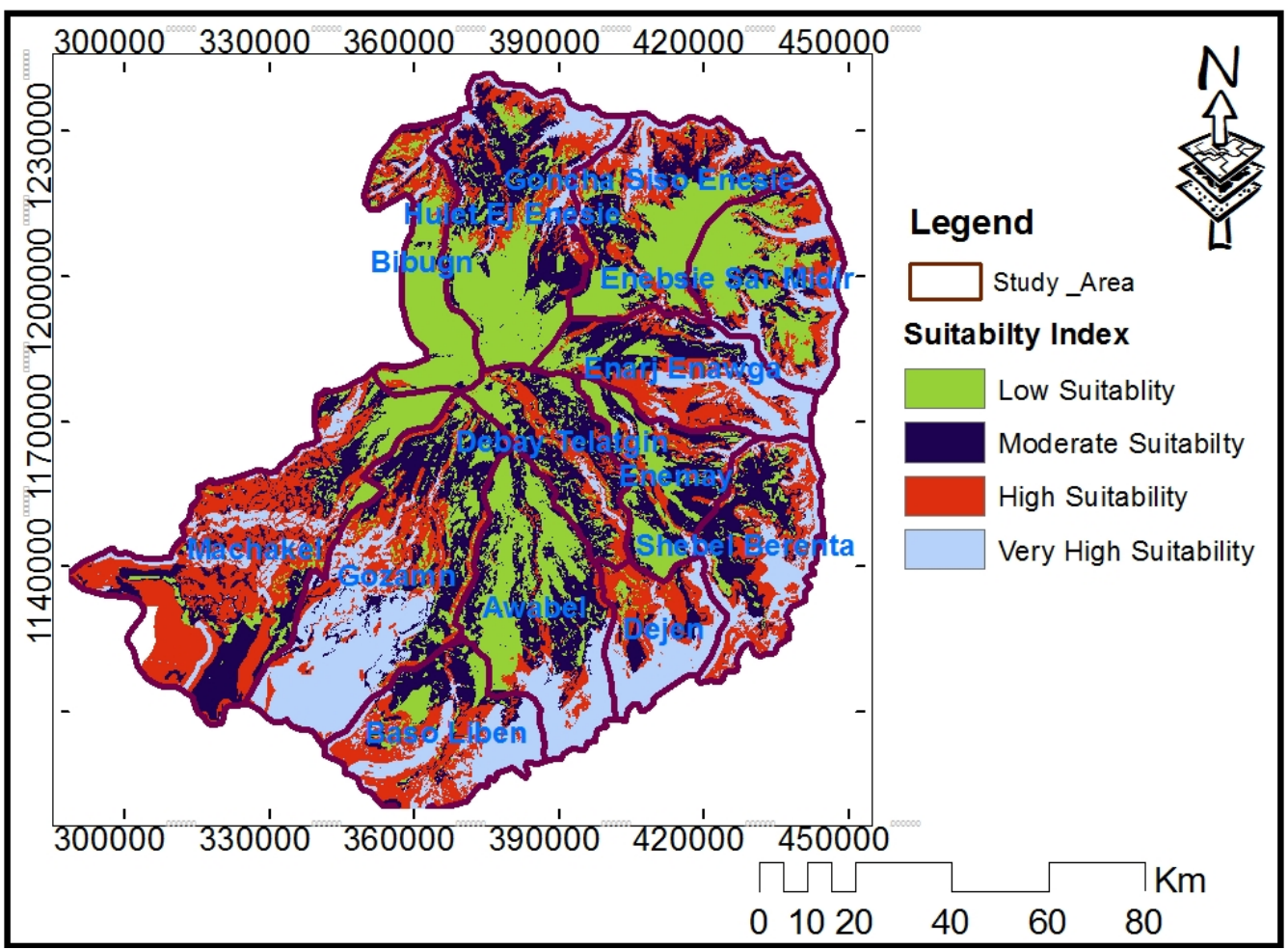

Fig.7: Malaria Risk map

In this study, for the purpose of identifying areas of malaria risk; population density, distribution of health stations, malaria hazard and land use land cover were used as input factors for malaria risk mapping. As a result, the risk map in figure 7 showed $986.82 \mathrm{Km}^{2}(29.83 \%), 816.02 \mathrm{Km}^{2}(24.66 \%), 810.21 \mathrm{Km}^{2}(24.49 \%)$, and $695.35 \mathrm{Km}^{2}(21.02 \%)$ of the total area is subject to low, moderate, high, and very high suitable for malaria risk level in the study area respectively. Hence, it is possible to conclude that the majority of the area (more than $79 \%$ ) is under very high risk of malaria. From the finding result, the woreda of Gozamen, Baso liben, Awabel, and Dejen are a very high risk of malaria. This is due to the topographical and environmental factors and also the poor health facility for the existing large number of population in the study area and the existence of suitable land uses and land covers for mosquito breeding.

\section{CONCLUSION}

This study has shown that GIS and MCA is important to identify malaria risk areas for malaria disease control. The malaria risk map was produced depending upon the overlay analysis of the malaria hazard map and some factors like land use land cover, population density, health stations. The result indicated that the majority of the area (more than $79 \%$ ) is under very high risk of malaria. From the finding result, the woreda of Gozamen, Baso liben, Awabel, and Dejen are a very high risk of malaria. This is due to the topographical and environmental factors and also the poor health facility for the existing large number of population in the study area and the existence of suitable land uses and land covers for mosquito breeding.

\section{REFERENCE}

A., A. (2014). GIS and Remote Sensing for Malaria Risk Mapping, Ethiopia. The International Archives of the Photogrammetry, Remote Sensing and Spatial Information Sciences.

Addisu W. (2015). Assessment of Control Measures and Trends of Malaria in Burie-Zuria District, West Gojjam Zone, Amhara Region, NorthWest Ethiopia. Malaria Research and Treatment , http://dx.doi.org/10.1155/2015/302194.

Ayalew S, M. H. (2016). Assessment of current malaria status in light of the ongoing control interventions, sociodemographic and environmental variables in Jiga Area, Northwest Ethiopia. PLoS ONE .

Betemariam G, a. Y. ( 2002). Severe malaria among children in Gambella region, western Ethiopia. Ethiopian Journal of Health Development. 16: 61-70.

Chakarova B, K. K. (2015). A Short Historical Overview Of Malaria In Worldwide And In Bulgaria. The Fight Against Malaria - The Main Task Of Sanitary Epidemiological Station In Stara Zagora In The First Year Of Its Opening. Trakia Journal Of Sciences, Vol. 13, Suppl. 2, Pp 151-154.

Emebet D, K. S. (2016). Malaria-risk assessment using geographical information system and remote sensing in Mecha district, West Gojjam, Ethiopia.Department of Zoological Sciences, Addis Ababa University. 
Mulugojjam Andualem, A. W. (2015). Assessment of Control Measures and Trends of Malaria in Burie-Zuria District, West Gojjam Zone, Amhara Region, North West Ethiopia. Malaria Research and Treatment .

Obsomer V, D. P. (2007). The Anopheles dirus complex: spatial distribution and environmental drivers. Malaria J. . 6:26.

Onyango E. (2016). An integrated risk and vulnerability assessment framework for climate change and malaria transmission in East Africa. Malaria Journal, 15(551), 1-12 .

S. Kannathasan, A. A. (2009). Identification of potential malaria risk areas of the Jaffna district of northern Sri Lanka: A GIS approach. J.Natn.Sci.Foundation Sri Lanka. 37 (3):223-225 .

Sujoy K., T. S. (2016). Integrating remote sensing and GIS for investigating malaria risk areas in morobe provincepapua new guinea”, International Journal of Current Research, 8, (08), 37476-37483.

W., T. (2016). Geographic Information System and Remote Sensing Based Malaria Risk Mapping: A Case of shone town administration, Southern Nations Nationalities and Peoples' Regional State. Addis Ababa University Msc Thesis .

World Health Organization, "World Malaria Report," Geneva, 2003. 